\title{
El periodismo taurino en la Historia del Periodismo Español
}

\author{
Ma Verónica de HaRo de SAN MATEO \\ Universidad de Murcia-España \\ mvdeharo@um.es
}

\section{Resumen}

La Fiesta de los Toros tiene presencia documentada en España desde el siglo XVI y aunque las amenazas de prohibición han sido constantes a lo largo de la Historia - cobrando especial vigencia durante los últimos años - la Tauromaquia ha llegado a nuestros días, conservando además, una presencia regular en los medios de comunicación. Este trabajo pone de relieve el periodismo taurino en el conjunto de la Historia del Periodismo Español, desde las primitivas Relaciones hasta el más moderno de los soportes, Internet.

Palabras clave: Periodismo - Historia - Tauromaquia - España

\section{The bullfighting journalism in the History of the Spanish Journalism}

\begin{abstract}
The Bullfight has presence documented in Spain from the 16th century and though the threats of prohibition have been constant along the History - receiving special force during the last years - the Bullfighting has come to our days, preserving in addition, a regular presence in the mass media. This work emphasizes the bullfighting journalism in the set of the History of the Spanish Journalism, from the primitive Relations up to the most modern of the supports, Internet.
\end{abstract}

Key words: Journalism; History; Bullfight; Spain

\section{Referencia normalizada:}

De Haro de San Mateo, M. V. (2013) El periodismo taurino en la Historia del Periodismo Español. Historia y Comunicación Social. Vol. 18. Nºspecial Diciembre. Págs. 643-652.

Sumario: 1. Introducción y metodología. 2. Los orígenes del periodismo taurino. 2.1. La primera crónica taurina publicada en un periódico. 3. La consolidación de la "revista de toros" en la prensa del siglo XIX. 4. El periodismo taurino en la "Edad de Oro" del periodismo español. 4.1. Los toros en el nacimiento de los medios audiovisuales: el cine y la radio. 5. La información taurina durante la guerra civil y el franquismo. 5.1. Los toros en No-Do y TVE. 6. El eco mediático de la Fiesta desde la Transición a la actualidad. 7. Referencias bibliográficas. 


\section{Introducción y metodología}

En las Relaciones u Ocasionales, en las Gacetas, en los periódicos del siglo XVIII y las revistas ilustradas del XIX, en los diarios de información del XX y también desde el nacimiento de la radio, la televisión en Internet, en todas las etapas de la Historia del Periodismo en España ha estado presente la información taurina. A pesar de ello, en las obras de carácter general dedicadas al estudio de esta disciplina en nuestro país, el argumento se trata, lamentablemente, muy de pasada. La excepción la constituyen las obras de Gómez Aparicio (1971) y Alejandro Pizarroso (1992) en las que el periodismo taurino es protagonista de sendos epígrafes. María Cruz Seoane y M ${ }^{a}$ Dolores Sáiz (1996) - en su tercer tomo de la "Historia del Periodismo en España"- le dedican mayor atención que en las obras anteriores (Seoane, 1983) y posteriores (Sáiz \& Seoane, 2007) pues en cada uno de los períodos considerados y dentro del apartado brindado a las revistas de espectáculos, aparece siempre un espacio titulado "Toros". Si las obras que estudian la Historia del Periodismo Español se ocupan modestamente del estudio del periodismo taurino, tampoco lo han hecho con mayor profundidad los trabajos más relevantes sobre la Historia del Toreo pues aunque en la mayor parte de los casos son frecuentes las referencias a las crónicas y los revisteros taurinos, ninguno de ellos se ha detenido a estudiar el fenómeno de la prensa taurina de cada época. Probablemente, el estudio más completo que sobre el periodismo taurino se ha realizado hasta la fecha esté incluido en varios tomos de la monumental obra "Los Toros" de Cossío y en la reedición que de la misma se ha hecho recientemente, en concreto el volumen ocho - titulado genéricamente "Literatura y Periodismo" - en el que se incluyen además dos nuevos artículos que no aparecen en la colección original: los titulados "Los toros y el periodismo" (Pizarroso, 2007) e "Internet y el planeta de los toros" (Moncholi, 2007).

La Fiesta de los Toros tiene presencia documentada en España desde el siglo XVI y aunque las amenazas de prohibición han sido constantes a lo largo de la Historia (Badorrey, 2009) - cobrando especial vigencia durante los últimos años - la Tauromaquia ha llegado a nuestros días, conservando además, una presencia regular en los medios de comunicación. Quizá por ello, en los últimos años, el tema ha suscitado el interés de algunos investigadores pero a pesar de que existen meritorias investigaciones parciales sobre la cuestión (De Haro, 2011a), aún no se ha realizado un estudio monográfico sobre la relación que los medios han tenido con la Fiesta ni una Historia del Periodismo Taurino en su conjunto.

El resultado de nuestro estudio - que ha consistido fundamentalmente en la revisión bibliográfica de los trabajos publicados sobre la materia - se propone constatar, por fuerza brevemente, cómo la información sobre el mundo de los toros está presente en el ruedo histórico de la prensa desde las primitivas Relaciones que se imprimen a finales del siglo XVI en España hasta las páginas web especializadas en el más moderno de los soportes, Internet, donde la información taurina ha experimentado un auge inusitado, cobrando un nuevo impulso que va más allá de la tradicional crónica taurina. 


\section{Los orígenes del periodismo taurino}

Coincidimos con Manuel Bernal en considerar que "la información taurina es, por lo menos, tan antigua como las remotas manifestaciones paleoperiodísticas y permanece indisolublemente unida al periodismo en todas sus etapas de gestación y desarrollo" (Bernal, 1997: 27). Ciertamente, la información taurina existe desde el inicio de la actividad periodística en España pues la Fiesta, en su fórmula caballeresca, tiene un reflejo muy considerable en las primitivas Relaciones y Ocasionales que se imprimen en nuestro país desde finales del siglo XVI. Cossío, en su obra monumental - Los Toros - recoge 270 entradas desde 1556 a 1846 (concretamente: 5 en el siglo XVI; 135 en el XVII; 83 en el XVIII y 23 en el siglo XIX) y hasta uno de los escritores más afamados del Siglo de Oro español - Francisco Gómez de Quevedo - se convirtió en cronista taurino para describirnos en verso "la Fiesta de toros, con rejones, al príncipe de Gales, en que llovió mucho", en la que Felipe IV intervino, alanceando un toro, en el año $1623^{1}$. Afirmar, no obstante, que la información taurina aparecida en estas Relaciones es equiparable a una crónica taurina, tal como la entendemos hoy en día, es un poco exagerado. Estos escritos, más que detenerse en el recuento pormenorizado de las suertes ejecutadas por los toreros o la descripción del comportamiento de los toros, se entretienen en narrar el adorno y boato que acompaña a este tipo de funciones. A pesar de ello "no faltan casos donde se describen los lances de los caballeros, la habilidad de los mismos, etc. como si de una revista de toros de nuestros días se tratase." (Pizarroso, 1993: 226)

La Tauromaquia está presente en este tiempo también en la Gaceta de Madrid, pues como periódico oficial de la Corte, se hace eco de todos los fastos y funciones celebradas en ésta y la Tauromaquia no es una excepción. A medida que el espectáculo taurino evoluciona y en el siglo XVIII alcanza regularidad, comienza a tener presencia continuada en los papeles periódicos como bien han estudiado Pizarroso (2004) y Cabrera y Artigas (1991), pero antes de que aparezca la primera crónica taurina en un periódico encontramos anuncios de los carteles de las corridas que debían celebrarse y hasta el resultado de las recaudaciones de tales festejos en las páginas del Diario de Madrid o del Memorial Literario, respectivamente.

\subsection{La primera crónica publicada en un periódico}

Firmada por "Un Curioso", la primera crónica taurina se publica precisamente en el Diario de Madrid, el 20 de junio de 1793. Su director, Santiago Thewin, tuvo el acierto de ofrecer la reseña a los lectores inaugurando una costumbre que llega a nuestros días. La crónica aparecida en la célebre cabecera fundada por Mariano Nipho estaba precedida por una breve carta en la que se podía leer:

"Muy Señores míos: Vmds. Suelen describir una maquina, extraer el argumento de las Comedias nuevas, hacer la descripción de una función extraña, como las que ha habido de los globos de Lunardi, pero nunca he visto descrita una función de Toros. Sin embargo, creo que el público lo agradecería: pero sea como fuere, hay vá 
la descripción de la fiesta última por si gustan darla a la prensa, mientras piensan en lo que han de dar por materia el día siguiente"2

La corrida caballeresca experimenta gran desarrollo entre los siglos XVI y XVIII, tal como hemos comentado. La Fiesta de los Toros es por entonces un espectáculo singular y periódico, independiente de otras celebraciones aunque relacionado con ellas y las suertes del toreo evolucionan a medida que la lidia se regula y surgen los primeros Tratados del arte de torear. A pesar de que ya por entonces es un fenómeno muy popular, o precisamente por ello, no le faltan ataques y de la misma manera que los periódicos registran la actualidad taurina, también pueden encontrarse en las publicaciones periódicas de corte ilustrado - como El Pensador, El Corresponsal del Censor, La Espigadera o incluso las "Cartas Marruecas" de Cadalso aparecidas en el Diario de Madrid - actitudes críticas contra la Fiesta.

\section{La consolidación de la "revista de toros" en la prensa del siglo XIX}

La información taurina se abre paso en los periódicos diarios de manera regular durante la segunda mitad del siglo XIX. La consolidación de la corrida como espectáculo y la profesionalización de la actividad taurina son procesos paralelos a la Revolución Industrial. En esos momentos, nuestro país asiste al nacimiento de la prensa de masas y los periódicos de información se hacen eco del resultado de los festejos a través de un género típicamente hispano: "la revista de toros" o "crónica taurina". José $\mathrm{M}^{\mathrm{a}}$ de Cossío (1985: 555) apunta que las "revistas taurinas" que acaban generalizándose en la prensa diaria del tercio medio del siglo XIX consisten generalmente en:

\footnotetext{
"La observación y recuento de las suertes; la estadística de los puyazos, banderillas, pinchazos y estocadas recibidos por cada toro; la reseña de los pelos y señales de éstos, hasta los detalles del vestido de los toreros, que parece recuerdo claro de la importancia que las viejas relaciones taurinas concedían a la parte suntuaria y pintoresca de los festejos, aparecen ya en estas crónicas, que merecen este título no como género periodístico, sino como depósito de noticias históricas relatadas en caliente, con la vista de impresión inmediata del suceso".
}

Paralelamente, aparecen las primeras publicaciones especializadas dedicadas exclusivamente al mundo de los toros y en ellas se recogen fundamentalmente crónicas de festejos celebrados pero también noticias relativas a los actores de la Fiesta y a la historia de la lidia. Poco a poco, la información crece en cantidad y variedad en los periódicos y en las revistas estrictamente taurinas. El afianzamiento de la corrida a pie y la consecuente proyección del torero como héroe popular y literario (González, 1988) propician la creación de las publicaciones especializadas dedicadas exclusivamente al "planeta de los toros". La precursora de éstas ve la luz en Madrid en 1819 con el título Estado que manifiesta las peculiaridades ocurridas en esta corrida. Pero hasta mediados de siglo no podremos hablar con propiedad de una prensa específicamente taurina regular. Algunos títulos de relevantes cabeceras taurinas de este tiempo son La Tauromaquia, Las Cartas Tauromáquicas, El Clarín o El Enano. Más 
importantes fueron El Mengue, con su redactor exclusivo Mariané; El Tábano; El Toreo, que empezó como suplemento de La Correspondencia Teatral en 1874 y que se va a prolongar hasta 1921 y El Tío Jindama, que apareció en noviembre de 1879.

Coincidiendo con el apogeo de la prensa diaria, ya en el último tercio del siglo, el 2 de abril de 1882 nace la revista La Lidia, que inmediatamente adquirió categoría literaria por la cuidada selección de sus redactores y colaboradores, además de distinguirse por la modernidad y excelencia de su presentación (Nieto, 1986).

Algunos de los grandes nombres del periodismo taurino de este siglo (Forneas, $2001)$ son: Santos López Pelegrín "Abenamar", que fue redactor en El Mundo y en El Correo Nacional; Serafín Estébanez Calderón, "El Solitario", que escribió jugosas crónicas taurinas entre 1839 y 1844 en El Correo Nacional y El Corresponsal; José de la Loma y Milego "Don Modesto", verdadero revolucionario de la crítica a la que consagró por entero su vida; Antonio Peña y Goñi, que escribió entre otras cabeceras en El Imparcial; y el zaragozano Mariano de Cavia "Sobaquillo", que hizo lo propio en El Liberal.

\section{El periodismo taurino en la "Edad de Oro" del periodismo español}

El siglo XX da comienzo "en un momento de plenitud de la Fiesta que se refleja sin duda en su prensa especializada y en la prensa diaria" (Pizarroso, 1993: 237) El fecundo primer tercio del siglo, con la rivalidad de Joselito y Belmonte en los ruedos coincide con la llamada "Edad de Oro" del periodismo impreso español. La proliferación de cabeceras taurinas en este tiempo es realmente significativa y es raro el año que en Madrid no se publican semanal y simultáneamente durante la temporada de toros al menos media docena de publicaciones taurinas.

Tras la muerte de Peña y Goñi en 1896, La Lidia comienza su decadencia y la mayor parte de sus colaboradores pasan a otra gran revista, Sol y Sombra, que en 1920 tenía una tirada aproximada de 3000 ejemplares. Otras cabeceras destacadas del primer tercio del siglo son Don Jacinto taurino, La Corrida o El eco taurino (que llegó a tener una tirada de 8000 ejemplares)

Gregorio Corrochano y César Jalón "Clarito", cronistas de Abc y The Kon Leche respectivamente, son referentes del periodismo taurino de esta época en la prensa informativa. El primero sucede a Manuel Serrano García Vao "Dulzuras" al frente de la cabecera fundada por Luca de Tena, fiel en su atención al mundo taurino desde su nacimiento. Por su parte, quien fuera ministro de Comunicaciones y redactor de $E l$ Liberal, escribirá finalizada la guerra civil en Informaciones las crónicas de la Plaza de Toros de Las Ventas, inaugurada en 1931. 


\subsection{Los toros en el nacimiento de los medios audiovisuales: el cine y la radio}

Durante la dictadura de Primo de Rivera - una época en la que no hay ninguna novedad en el ritmo de publicación de las revistas taurinas especializadas o en el eco de la actualidad taurina en la prensa informativa - se produce un hito digno de ser resaltado. Una de las primeras retransmisiones radiofónicas que se realizan desde el exterior es concretamente la de una corrida que se celebra en la Plaza Vieja de Madrid, el 8 de octubre de 1925, en la que participaba Juan Belmonte (Garitaonaindía, 1988: 41)

Antes de estar presente en la radio, el mundo taurino había quedado recogido por el nuevo invento que iba a revolucionar la historia del entretenimiento a partir de su nacimiento: el cine. El 15 de mayo de 1896, tan sólo seis meses después del nacimiento del cinematógrafo, un operador rodaba en la Plaza de Madrid una película, de apenas un minuto de duración, titulada "Llegada de los toreros a la plaza". La cinta recogía exactamente la escena que describía el título - el momento de la llegada de los matadores al recinto taurino en coche de caballos - pero no mostraba ninguna escena de la lidia. Dos años después se produjo el primer intento de filmar el toreo. "Gran corrida de toros" era el título del film protagonizado por el torero Luis Mazzantini. Se proyectó en el Teatro Principal de Jerez de la Frontera el 27 de diciembre de 1898. Ese mismo año, los operadores de Lumière incluyeron en su catálogo doce títulos alusivos a la fiesta taurina - de los treinta y siete capítulos que se rodaron ese año en España bajo el título general de "Courses de Taureaux". Por vez primera se lograban capturar imágenes en movimiento de una corrida completa, "imágenes que recogían perspectivas amplias sin atreverse a intercalar, como se haría bastantes años después, detalles cercanos" (Fernández, 2007: 311-312).

\section{La información taurina durante la guerra civil y el franquismo}

Al igual que sucedió en todos los órdenes de la vida, la guerra civil truncó la suerte de muchas publicaciones taurinas especializadas pero la información de los pocos festejos que se celebraron en uno y otro bando fue recogida por los periódicos. Finalizada la guerra, el panorama periodístico madrileño era radicalmente distinto a los años anteriores. Carlos de Larra "Curro Meloja" hace verdadera información taurina en la radio española con su programa nocturno "Tauromaquia, revista radiofónico-taurina". "Clarito", Gregorio Corrochano, "Don Ventura", "R. Capdevila", "Selipe", "K-Hito" o Díaz Cañabate son los protagonistas de la prensa escrita.

En 1944 y de manos de Manuel Fernández cuesta nace una publicación que hasta su desaparición en 1977, llena toda una época de toros, El Ruedo (Ramón, 2009). Otra gran revista que alberga información taurina en este periodo es el semanario Dígame. 


\subsection{Los toros en No-Do y TVE}

Naturalmente, como primer espectáculo de masas del país, los toros también están presentes en No-Do y gracias a las numerosas piezas informativas de contenido taurino, los españoles de la época pudieron apreciar las tauromaquias y conocer los éxitos de las figuras en las principales ferias de España y México durante décadas. A pesar de su enorme importancia, el handicap de No-Do era su incapacidad para mostrar a los espectadores el resultado de los festejos en tiempo real. Las retransmisiones en directo que pocos años después posibilitaría la televisión supondrán un enorme salto cualitativo en este sentido. La primera de ellas se produce en el tiempo de emisiones experimentales del nuevo medio en España y es que, al igual que sucede con la radio, los primeros pasos de la televisión en nuestro país están ligados a la Fiesta de los Toros.

Unos días después del exitoso experimento de Philips en la XVI Feria Oficial e Industrial de Muestras que se celebra en Barcelona entre el 10 y el 29 de junio de 1948, Radio Corporation of America intenta abordar la primera prueba de transmisión de un evento al aire libre. Para dicha prueba, Gabriel Soria propuso la filmación de un espectáculo taurino "por ser el espectáculo más español" y así se decidió que el evento a transmitir fuera la corrida de toros prevista para el 8 de agosto en la plaza de Vista Alegre (De Haro, 2012).

Durante los primeros años, los periodistas de los medios audiovisuales - al igual que los que ejercen esta especialidad en la prensa escrita - informan de la Fiesta desde una perspectiva más publicitaria que informativa. Matías Prats, Rafael Campos de España y Manuel Lozano Sevilla, entre otros, se encargan de la información taurina en RNE y TVE.

\section{El eco mediático de la fiesta desde la transición a la actualidad}

La revolución de Manuel Benítez "El Cordobés" es paralela a la que experimenta el medio televisivo en los años sesenta. La muerte del dictador y la transición democrática coinciden con una etapa de crisis para la Fiesta. En 1977 desaparece El Ruedo pero un año antes ve la luz en Valencia la revista Aplausos, decana de la prensa taurina especializada actual. José Luis Suárez Guanes, Joaquín Jesús Gordillo o Luis García son los periodistas que la impulsan. En el panorama de la prensa surgen nuevos valores que revolucionan la crítica. Vicente Zabala, Carlos de Rojas, Alfonso Navalón, Manuel Molés, Mariví Romero, Joaquín Vidal o "Barquerito" son algunos de los nombres que vienen a regenerar el periodismo taurino y a asentarlo en nuevas cabeceras como Diario 16 o El País.

Actualmente, la mayoría de los periódicos españoles ofrece información, fundamentalmente crónicas, de los principales seriales taurinos (De Haro, 2009b). En este contexto, las páginas de información taurina surgidas en la Red en los últimos años de 
la década de los noventa, han apostado por la información de actualidad, el desarrollo de los contenidos multimedia, la participación de los usuarios y la integración de servicios útiles como la venta de entradas. Algunos ejemplos son www.mundotoro. com o www.burladero.com. Internet ha propiciado, en definitiva un enriquecimiento sustancioso en la parcela de la información taurina de actualidad y parece lógico que el aficionado a la Fiesta haya recibido con entusiasmo la llegada de nuevas posibilidades comunicativas que además le confieren un alto grado de participación (De Haro, 2006)

La información taurina está presente en la radio en los programas específicos "Clarín"(RNE), "Los Toros"(Cadena SER), "El Albero"(COPE) o "Carrusel Taurino" (Canal Sur Radio). En lo concerniente al medio televisivo, TVE decidió poner punto final a las retransmisiones taurinas al término de la temporada 2006. Desde entonces, los toros se han asomado a los informativos de esta cadena en contadas ocasiones pero se mantiene en parrilla el programa especializado, "Tendido Cero". En contra de la escasa atención que el ente público dedica a la Tauromaquia, las cadenas autonómicas ofrecen información taurina de forma regular aunque, en líneas generales, su cobertura se limita al ámbito local. Telemadrid, Castilla La Mancha Televisión o Canal Sur son algunos ejemplos. En cuanto a las cadenas privadas - a excepción de Canal Plus que ofrece a sus abonados una extraordinaria cobertura de las principales ferias y programas de original formato como "68 pasos" o "El kikirikí" - sólo se acercan a la Fiesta en momentos muy puntuales. Ciertamente, pocos recuerdan ya la febril atención que dispensaron Antena3 y Telecinco al mundo taurino, mediados los noventa, cuando las crónicas al término de una corrida en los últimos minutos del telediario o las retransmisiones de festejos fueron harto frecuentes.

Por último, las publicaciones taurinas especializadas son un referente obligado para el seguimiento de la actualidad derivada del mundo de los toros porque ofrecen una información contextualizada en oposición a la fragmentaria atención que el resto de medios dedica al mundo de los toros (De Haro, 2009a y 2011b). Entre las publicaciones más importantes cabe citar Aplausos, 6TOROS6 y Cuadernos de Tauromaquia. No obstante, la información y las crónicas recogidas en los periódicos son un factor del que no puede prescindirse para conocer el estado actual de la Fiesta.

\section{Referencias bibliográficas}

ALTABELLA, J. (1965). Crónicas taurinas, Madrid: Taurus.

BADORREY MARTÍN, B. (2009). "Principales prohibiciones canónicas y civiles de las corridas de toros". En: Provincia, $\mathrm{n}^{\circ}$ 22. Venezuela: Universidad de los Andes. p. 107-146. Disponible en: http://redalyc.org/articulo.oa?id=55513213006 [28-10-2013]

BERNAL RODRÍGUEZ, M. (1997). La crónica periodística. Tres aproximaciones a su estilo. Sevilla: Padilla Libros Editores y Libreros. 
CABRERA BONET, R.; ARTIGAS, $\mathrm{M}^{\mathrm{a}}$ T. (1991). Los Toros en la Prensa Madrileña del siglo XVIII. Madrid: Consejería de Cultura de la CAM.

COSSÍO, José M ${ }^{\mathrm{a}}$ (2007). Los Toros. Literatura y Periodismo, vol. 8. Madrid: Espasa Calpe.

(1985). Los Toros. Tomo IV. Madrid: Espasa Calpe.

DE HARO DE SAN MATEO, M ${ }^{\mathrm{a}}$ V. (2012). "Los toros en la prehistoria de la televisión". En VVAA. (2012). Comunicación y Riesgo. Programación y producción de contenidos televisivos durante el franquismo (1956-1975). Tarragona: Asociación Española de Investigación en Comunicación y Universitat Rovira i Virgili. Disponible en: http://www.aeic2012tarragona.org/comunicacions_cd/ok/185.pdf [28-10-2013]

(2011a). "El estudio del periodismo taurino: revisión y actualización bibliográfica". En: Doxa Comunicación, ${ }^{\circ}$ 13, Madrid: Universidad CEU San Pablo. p.43 -65. Disponible en: http://www.humanidades.uspceu.es/pdf/doxa132.pdf [28-102013]

(2011b). "La evolución estratégica de la prensa especializada en la historia del periodismo. Un estudio de caso". En: Revista de Comunicación de la Sociedad Española de Estudios de Comunicación Iberoamericana, $\mathrm{n}^{\circ}$ 25, Madrid: Sociedad Española de Estudios de Comunicación Iberoamericana. p. 25-42. Disponible en: http://www.seeci.net/Numeros/Numero\%2025/Vero.pdf [28-10-2013] (2009a). 6TOROS6, revista de actualidad taurina. Tesis doctoral. Madrid: Universidad Complutense de Madrid.

(2009b). "Un ejemplo de realidad fragmentada: la información taurina en los medios de comunicación españoles". En: Vivat Academia, nº 109, Madrid: Universidad Complutense. p. 1-18. Disponible en: http://pendientedemigracion.ucm.es/ info/vivataca/numeros/n109/Num109/PDFs/n109-3.pdf [28-10-2013]

(2006). "10 años de información taurina en Internet. Un nuevo modelo de periodismo taurino". En VVAA. (2006). Análisis y propuestas en torno al periodismo digital, Actas del VII Congreso Nacional de Periodismo Digital. Huesca: Asociación de la Prensa de Aragón. p. 214-224.

FERNÁNDEZ CUENCA, C. (2007). "Los toros en el cine". En Cossío (2007). Los Toros. Vol. 10. Madrid: Espasa. p. $301-577$.

FORNEAS, C. (2001). Periodistas taurinos españoles del siglo XIX. Madrid: Fragua. GARITAONAINDÍA, C. (1988). La radio en España, 1923-1939. De altavoz musical a arma de propaganda. Bilbao: Universidad del País Vasco.

GÓMEZ APARICIO, P. (1971) "Periodismo taurino". En: GÓMEZ APARICIO, P. (1971). Historia del periodismo español, t. II, De la Revolución de septiembre al Desastre colonial. Madrid: Editora Nacional. p. 582-599.

GONZÁLEZ TROYANO, A. (1988). El torero, héroe literario. Madrid: Espasa.

MONCHOLI CHAPARRO, M. Á. (2007). "Internet y el planeta de los toros" En: Cossío (2007). Los Toros. Literatura y Periodismo. Vol. 8. Madrid: Espasa. p. 680-703.

NIETO MANJÓN, L. (1986). La Lidia. Modelo de Periodismo. Madrid: Espasa Calpe. 
PIZARROSO QUINTERO, A. (2007). "Los toros y el periodismo". En: Cossío (2007). Los Toros. Literatura y Periodismo. Vol. 8. Madrid: Espasa. p. 650-679. (2004). "Prensa y toros en el siglo XVIII". En: Revista de Estudios Taurinos, $\mathrm{n}^{\mathrm{o}}$ 18. Sevilla: Fundación de Estudios Taurinos. p. 205-249.

(1993). "Los toros y los medios de comunicación". En: Anuario del Departamento de Historia de la Comunicación, $\mathrm{n}^{\circ}$ 5. Madrid: Universidad Complutense. p. 225-248.

(1992). "Algo genuinamente español: el periodismo taurino". En: De la Gazeta Nueva al canal Plus. Breve historia de los medios de comunicación en España. Madrid: Editorial Complutense. p. 74-77.

RAMÓN CARRIÓN, J. L. (2009). Revista El Ruedo. Treinta y tres años de información taurina en España (1944-1977). Tesis doctoral. Madrid: Universidad Complutense de Madrid.

SÁIZ, Ma D.; SEOANE, M ${ }^{\mathrm{a}}$ C. (2007). Cuatro Siglos de Periodismo en España, De los avisos a los periódicos digitales. Madrid: Alianza.

(1996). Historia del periodismo en España, 3. El siglo XX: 1898-1936. Madrid: Alianza.

SEOANE, M ${ }^{\mathrm{a}}$ C. (1983). Historia del Periodismo en España, 2, el siglo XIX. Madrid: Alianza.

Diario de Madrid, 20-6-1793.

\section{Notas}

1 El texto completo de esta crónica puede encontrarse en ALTABELLA, J. (1965). Crónicas taurinas, Madrid: Taurus, p.49-54.

2 Diario de Madrid, 20 de junio de 1793.

\section{La autora}

Ma Verónica De Haro De San Mateo. Licenciada y Doctora en Periodismo por la Universidad Complutense de Madrid. Profesora del Departamento "Información y Documentación", de la Facultad de Comunicación y Documentación de la Universidad de Murcia desde 2005, sus principales líneas de investigación son el estudio de la Historia de la Comunicación Social y la Historia del Periodismo. Forma parte de la Asociación de Historiadores de la Comunicación, la Asociación Española de Investigadores en Comunicación y la Asociación PILAR. 